\title{
Factors Affecting Chinese Consumers' Impulse Buying Decision of Live Streaming E-Commerce
}

\author{
Yue Huang ${ }^{1} \&$ Lu Suo $^{1}$ \\ ${ }^{1}$ Stamford International University, Bangkok, Thailand \\ Correspondence: Yue Huang, Stamford International University, Bangkok, Thailand. E-mail: 7079728@qq.com
}

Received: March 26, 2021

Accepted: April 5, $2021 \quad$ Online Published: April 27, 2021

doi:10.5539/ass.v17n5p16

URL: https://doi.org/10.5539/ass.v17n5p16

\begin{abstract}
From the perspective of consumers, this research studied four factors including price promotion, time pressure, interpersonal interaction and visual appeal influencing the impulse buying decision of live streaming e-commerce consumers in China. This research used a quantitative design by developing questionnaires to collect data through the convenience sampling approach from 477 Chinese users who has live streaming shopping experience in social commerce platform Taobao.com. within the past 1 year in Kunming, City. Structural Equation Model (SEM) was used to analyze the data and the hypotheses accordingly. The results confirmed that price promotion, time pressure (promotional time limit, perceived opportunity cost), interpersonal interaction (consumer-streamer interaction, consumer-consumer interaction) and visual appeal these six factors have a significantly positive effect on consumer impulse buying decision. Meanwhile, perceived risk was found negatively related to consumer impulse buying decision. Besides, price promotion and visual appeal played the most important role in influencing consumer impulse buying decision of live streaming than any other factors. Additionally, the results also show that the promotion, the perception of opportunity cost, the interpersonal interaction (the interaction between consumers and streamers, the interaction between consumers), and the visual appeal all have a significant negative impact on consumers' perceived risk. However, for time limit of time pressure, our research hypothesis that promotion time limit has a significant negative effect on consumers' perceived risk has not been verified. Finally, perceived risk was found plays a mediating role in the relationship between price promotion, perceived opportunity cost, interpersonal interaction, visual appeal and impulse buying decision. However, it did not play a mediating role in the effect of promotion time limit on impulse buying decision. The findings suggest that managers and merchants of live streaming e-commerce should make a reasonable price promotion plan and provide good visual experience for consumers, at the meantime, strengthen interpersonal interaction and try to reduce the purchase risk of consumers.
\end{abstract}

Keywords: China, Impulse buying decision, Live streaming e-commerce, Perceived risk, S-O-R model

\section{Introduction}

Live streaming e-commerce has been growing in China recent years. It combines live streaming video experience with online shopping experience to provide consumers with commodities-related video content to influence their purchase decisions and promote the conclusion of transactions between buyers and sellers (Yang $\&$ Lee, 2018). With the development of e-commerce and the widespread popularization and application of the Internet, live streaming e-commerce has become an important retail e-commerce model. In China, at present, many retail e-commerce platforms has launched the operation mode of live-streaming e-commerce, such as Taobao Live, Red book, Tik Tok, etc. Taobao live streaming is a representative product in the field of live streaming e-commerce (Huang, 2018). The users of Taobao live streaming platform include three roles: merchants, streamers and consumers. Merchants are providers of products and services that would like to increase sales and brand awareness. By providing live streaming content, streamers sell goods and services for merchants and help merchants to promote their brands. Streamers themselves could also act as merchants. Consumers are the receivers of information. By watching live streaming video, consumers could meet their both purchasing needs and entertainment needs (Yang \& Lee, 2018). Taobao Live streaming was founded in 2016. Since its establishment, it has achieved rapid growth of business. In 2018, the conversion rate of store entry exceeded $65 \%$ and the turnover exceeded 100 billion yuan, creating a brand-new market, so live streaming e-commerce has become an important marketing channel currently (Huang, 2018). In the whole consumption 
process of live streaming e-commerce, streamers' recommendation, consumers' feedback, discounts, emotional drive and other factors may stimulate consumers' demand, stimulate their purchase motivation, and then generate purchase behavior. Therefore, the topic merchants need to deliberate is that how to develop effective marketing programs, enhance consumers' impulse purchase desire, and promote the completion of the transaction between the buyer and the seller. Most of the existing researches on impulse buying mainly focus on traditional e-commerce (Fajar, Ketut \& Maulita, 2020; Seema, Richa, Vikas, \& Anita, 2019; Umair, Peng, Muhammad, Chen, \& Zubair, 2018). According to the prior studies, the influencing factors of impulse buying could be summarized into two aspects: internal factors and external factors. Internal factors include demographic characteristics, personal factors, etc. External factors, namely situational factors, refer to the specific situation that consumers are in, such as product, environment, time, interaction, etc. (Nasreen et al., 2015; Louis et al., 2016; Li et al., 2018). Live streaming e-commerce is an emerging e-commerce model developed on the basis of traditional e-commerce, and it is an upgrade of traditional e-commerce. However, compared with the booming field of live streaming in practice, there is a lack of in-depth research and discussion on impulse purchase behavior under its background. Therefore, based on management, psychology and marketing, unlike previous studies, this paper takes Taobao Live Streaming as an example to study and explore the influencing factors and influencing mechanism of consumers' impulse buying behavior in live e-commerce. Our results could provide a theoretical basis for the development of marketing strategies of live streaming merchants. When making marketing strategies, merchants would first consider the factors that have a greater impact on consumers' impulse purchase intention, so as to provide consumers with a better shopping experience and then enhance consumers' purchase desire.

This research is structed as follows. Firstly, the literature review and relevant generalizations are defined, and then the hypotheses and conceptual framework are put forward according to the relevant theories. Thereafter, the research methodology is discussed, and the data analysis and hypothesis testing are carried out in the next chapter. Finally, discussion, implications and limitations of this study and recommendations for future studies are given in the last section.

\section{Literature Review}

\subsection{S-O-R Model}

S-O-R (Stimulus-Organism -Response) model is derived from psychology. This model effectively explains the influence of external environment on human behavior (Mehrabian \& Russell, 1974). Later, as environmental psychology, it has been widely applied in retail environments to study the influence of environmental factors on consumer behavior in traditional stores and online stores (Figure 1). This model shows that physical environment, as an external stimulus, will influence the occurrence of approach or avoidance behavior by influencing people's internal organism state (Mehrabian \& Russell, 1974). Stimulus variables are the stimulus factors that may cause changes in consumers' cognition and emotions in the shopping environment (Wu, 2012). Organism is an internal process link the external stimulus and the final response. In this process, the external stimulus was transformed into effective information, which serves as the basis for subsequent behavior. Response is the behavioral result of the final approach or distancing of the stimulus object, including psychological response and behavioral response. In short, the S-O-R model states that there is a stimulus that triggers a response based on the internal feelings or behavior of an organism (person).

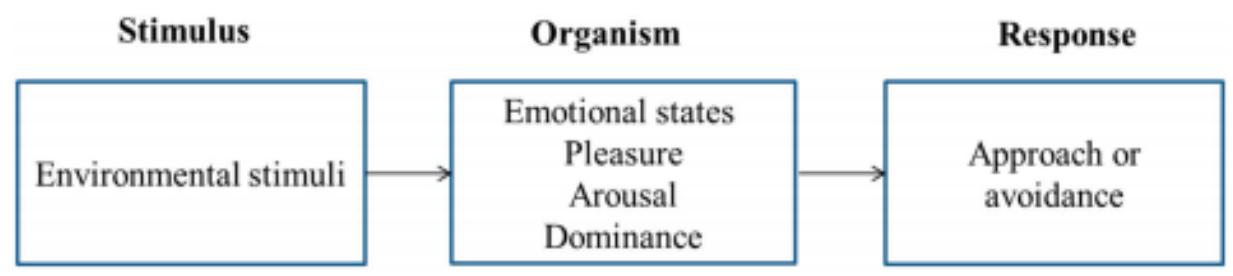

Figure 1. Stimulus-Organism-Response Model

Source Mehrabian \& Russell (1974)

Donovan and Rossiter (1982) applied the S-O-R model to the retail environment for the first time to study the influence of the atmosphere of the retail environment on consumers' purchasing behavior. With the development of online shopping, S-O-R model has been widely used in the field of online retail. Based on the S-O-R model, Yang (2009) studied the purchase intention of consumers in the online shopping environment. His results showed that the better the atmosphere and image of the online store and the higher the perceived quality, the stronger the 
purchase intention of consumers would be. He and Gong (2010) studied the impact of online shopping experience on consumers' behavioral tendency based on S-O-R model. The study revealed that shopping experience had little direct impact on consumers' behavioral tendency, and it mainly influenced customers' behavior indirectly through influencing consumers' emotions and trust. Zhao (2010) applied the S-O-R model to the research on impulsive buying of online consumers, and the results showed that environmental factors of websites could indirectly influence consumers' impulsive buying behavior by affecting their emotions. Based on the specific characteristics of live streaming e-commerce and S-O-R model, this study explores the influencing factors and influencing mechanism of consumers' impulse buying behavior of live streaming e-commerce.

\subsection{Impulse Buying Decision}

Impulse buying behavior is an unplanned decision to buy a specific product or a service, which before a real purchase (Cangelosi \& Dill, 1964; Liu \& Li, 2008). Parsad (2020) describes the impulsive buying pattern, which occurs when a consumer experiences an expected, strong, and persistent impulse to buy something immediately. Weinberg and Gottwald (1982) pointed out the impulse buying are the consumer due to the stimulation of the shopping environment and the intense emotional reactions and take immediate purchase behavior in the process of buying. Rook (1987) believes that impulse buying behavior is a behavior that occurs when consumers enjoy themselves more than they control themselves. In the absence of rational analysis, consumers make a quick purchase decision because they are immersed in the joy of obtaining a certain product while ignoring other choices. As we mentioned earlier in introduction, the influencing factors of impulse buying could be summarized into two aspects: internal factors and external factors. Nasreen et al. (2015) found that demographic factors are the most important influencing factors for consumers to have impulse buying behavior, followed by situational factors and personal factors. Li and Cui (2010) conducted a study on the specific situational factors influencing consumer behavior, pointing out that the main situational factors influencing consumer behavior include six factors, namely psychology, environment, marketing, time, material and interaction. In their study, individual psychological factors were attributed to the category of situational factors. Louis et al. (2016) showed that web page design and promotional activities positively influence consumers' impulse buying behavior. Li et al. (2018) found both the quality and quantity of online comments have a positive impact on consumers' impulse buying behavior. Relevant studies have been found that the probability of consumers' impulse buying behavior is proportional to their age and income, and female consumers are more likely to have impulse buying behavior than male consumers (Yang \& Lu, 2013). Promotional activities, advertisements, store decoration style, background music, smell and other marketing stimuli could stimulate consumers to make impulse purchases (Peck, 2003). In addition, personal factors such as emotion, lack of control, hedonism, and impulsivity are closely related to consumers' impulsive buying behavior. Based on the above research, this paper proposes that consumers' impulse buying is mainly influenced by personal characteristics and situational factors. Personal characteristic factors include demographic characteristics and personal factors. Situational factors are the specific situation during the whole shopping process, including psychological, marketing, product, environment, time, interaction and other factors. Factors such as promotion, website quality, online word-of-mouth, product introduction and other factors are the main influencing factors of consumers' purchasing behavior in traditional e-commerce online shopping (Xiong, 2017). Live streaming e-commerce is an emerging e-commerce model developed on the basis of traditional e-commerce, and the above influencing factors also have a significant impact on the impulse buying behavior of consumers in live streaming e-commerce. In addition, it is easy to find that stronger promotion activities, more intuitive product display and more frequent interpersonal interaction in live streaming e-commerce. Hence, compared with traditional e-commerce, consumers are more likely to be encouraged to have impulse buying behavior in live streaming e-commerce.

\subsection{Price Promotion}

Price promotion is a common way of promotion in daily life, mainly including two types of promotion: one is the direct price discount, that is, by directly reducing the sales price of goods to give the consumer price concessions, such as discounts, coupons, full reduction, etc.; The other one is indirect price preference, is through giving the additional income different from the original price of the commodity, such as additional gifts, lottery, product quality assurance, etc. are indirect price preference. Zhao and Luo (2008) analyzed the promotion activities of e-commerce websites such as Dangdang and Taobao, and summarized eight commonly used promotion methods on e-commerce platforms, including discount, special price, lottery, coupon, large-volume discount, freight discount, flash sale, and limited promotion. In live streaming e-commerce, direct price promotion generally include: discount, coupon, full reduction, cash return, shopping voucher, time-limited low-price secs kill, limited low price secs kill, etc., while indirect price discounts include additional gifts, lottery, etc. 


\subsection{Time Pressure}

As for the sources of time pressure, scholars' studies mainly include two viewpoints: one is that time pressure comes from time limitation. Ariely and Zakay (2001) believed that time restriction would cause time pressure, which would further affect individual psychological and emotional changes. There is no time pressure when individuals do not perceive time constraints. Another view holds that the generation of individual time pressure is closely related to the perception of opportunity cost caused by individuals giving up buying or delaying decisions in time emergency situations. Perceived opportunity loss will cause individuals to have anxiety and thus form time pressure. Payne et al. (1996) mentioned that individuals will hesitate in the speed of decision-making, because too fast decision-making may affect the quality of decision-making, and too slow or delayed decision-making may lead to the loss of relevant opportunities. Rieskamp and Hoffrage (2008) showed that time constraints allowed decision makers perceive the loss of opportunities, thus enhancing their time pressure and affecting the quality of decision making. Hence, two aspects will lead to time pressure, one is the time limit of promotion; the second is the perception of opportunity cost, that is, in a very short time, if consumers give up or delay the purchase, they will perceive the opportunity that may be lost.

\subsection{Interpersonal Interaction}

Interpersonal interaction is a communicative process in which two or more people exchange information, feelings and meaning through verbal and non-verbal information (Zhao, Wang, \& Zhou, 2015). Interaction could decrease transactional distance and help to deep understand each other. Interpersonal interaction in live streaming e-commerce includes two aspects: the interaction between consumers and streamers, and the interaction between consumers. Therefore, interpersonal interaction here means the process of information exchange through the internet among consumers and streamers and other consumers.

\subsection{Visual Appeal}

Sensory marketing could trigger consumers' feelings, influence their perception and judgment, and then influence consumers' behavior (Krishna, 2012). "Vision" is a common cognitive way of human beings. As an incentive factor, it is quickly able to attract the attention of consumers and stimulate consumption to produce psychological and cognitive changes. Liu (2013) pointed out that visual merchandising is a way by showed consumer goods information to achieve the goal of boosting sales. It is to stimulate the demand of consumers by bringing visual impact to them, and then urge them to have buying intention. Meanwhile, the application of visual merchandising could deepen consumers' impression on the brand and enhance the brand influence.

\section{Hypotheses and Conceptual Framework Development}

\subsection{The Effect of Price Promotion on Impulse Buying Decision}

In the purchase process, there are many factors that affect consumers' impulse purchase, but the most likely to enhance consumers' impulse purchase behavior is the price incentive, because the price has an essential impact on consumers' purchase decision, especially for those consumers who are more sensitive to the price. Price promotion is an "economic incentive" in promotional activities, in which consumers hope to obtain goods of the same or higher quality at a lower price, or to purchase more goods at a constant price. Price promotion could improve consumers' perceived value by delivering profit information, thus changing their perception of goods and influencing their purchasing decisions. Therefore, price promotion is a key factor that affects the impulse purchase behavior of consumers. Li et al. (2018) stated that price promotion directly or indirectly positively influences consumers' impulsive buying behavior. Dawson and Kim (2010) mentioned that both price discounts and additional giveaways can enhance consumers' impulse purchase intention. Yin (2013) found that price discounts have a positive impact on consumers' purchasing behavior, and different price promotion methods have different effects on consumers' impulse buying. Based on this, this paper proposes the first hypotheses:

H1: Price promotion has a significant positive impact on consumers' impulse buying decision.

\subsection{The Effect of Time Pressure on Impulse Buying Decision}

Wang and Liu (2008) revealed that under high time pressure, no matter which style is attributed to consumers, the quality of their decisions will be reduced. Aminilari and Pakathm (2005) proposed that the greater the perceived opportunity cost of consumers is, the greater the time pressure will be caused, which will lead to the sense of urgency, anxiety, not buying regret and other emotions. In order to alleviate this emotion, consumers will make decisions and judgments based on intuition, so it is easy to have the desire to buy impulsively. Wu and Huan (2010) found that consumers with high time pressure or rich economy have a higher degree of impulse buying. Xie (2015) conducted situational simulation experiments on the relationship between consumers' expected regret direction and impulse purchase under different time pressures, and the results revealed that in the 
presence of time pressure, the impulse purchase intention of consumers with promoting focusing tendency and defensive focusing tendency was both stronger than that without time pressure. In live streaming e-commerce, live seckill is adopted to carry out promotional activities. In a limited time, consumers need to make a quick purchase decision. Therefore, time pressure will exert a certain influence on consumers' impulse purchase desire. Hence, we put forward the following hypotheses:

H2a: Promotion time limit has a significant positive effect on consumers' impulse buying decision;

$\mathrm{H} 2 \mathrm{~b}$ : Perceived opportunity cost has a significant positive influence on consumers' impulse buying decision.

\subsection{The Effect of Interpersonal Interaction on Impulse Buying Decision}

Currently, more and more scholars have carried out researches on the relationship between interpersonal interaction and consumers' purchasing decisions. There are mainly two views. One is that interpersonal interaction directly influences consumers' impulse buying behavior (Shen \& Zhao, 2018). Larose (2001) pointed out that the feedback of buyers on goods will prompt consumers to make an immediate purchase. Another view is that there is an indirect effect between interpersonal interaction and consumers' impulse buying behavior. Zhang et al. (2019) found interaction in online communities has a significant impact on consumers' impulse buying behavior, and cognition and emotion play a mediating role in it. Chen et al. (2018) revealed that the interactive atmosphere of online communities would positively influence the community consciousness of community members and further promote consumers' impulse buying behavior. Jiang et al. (2014) stated that online interaction would create a sense of presence among consumers, which would further affect consumers' impulse buying behavior. Zhang and Wei (2019) found that interpersonal interaction between users positively impact on their perception of pleasure, which in turn would enhance users' impulse buying decision. In live streaming e-commerce, consumers could have real-time interaction with streamers and other consumers at any time according to their own needs, so as to have an in-depth understanding of the quality and function of products, and then make purchase decisions. Based on this, we put forward the following hypotheses:

$\mathrm{H} 3 \mathrm{a}$ : The interaction between consumers and streamers has a significant positive impact on consumers' impulse buying decision;

$\mathrm{H} 3 \mathrm{~b}$ : The interaction between consumers has a significant positive influence on consumers' impulse buying decision.

\subsection{The Effect of Visual Appeal on Impulse Buying Decision}

Visual merchandising has become an essential marketing means in the field of e-commerce. Zhao et al. (2014) mentioned that online commodity display could make consumers generate virtual sense of touch, which can enhance consumers' purchase desire in online shopping. Yang et al. (2017) showed that the product mini-video display of WeChat business not only has a direct positive influence on consumers' impulse buying behavior, but also has an indirect positive influence on impulse buying behavior through virtual touch. Liu et al. (2013) stated that visual appeal is able to stimulate the excitement of users and stimulate their emotional appeals. In the online shopping environment, GIFs, videos and other information released by merchants will arouse consumers' strong interest, make them have good associations, and then generate the motivation and willingness to buy. Live streaming e-commerce providers show products to consumers through real-time live streaming videos. Streamers' display and explanation of products, clothing fittings and cosmetics trial can arouse consumers' interest, stimulate consumers' beautiful associations, and then stimulate consumers' desire to buy. Based on this, we propose the following hypotheses:

H4: Visual appeal has a significant positive impact on consumers' impulse buying decision.

\subsection{The Effect of Perceived Risk on Impulse Buying Decision}

Perceived risks refer to the spirit cost associated with customers' purchasing behavior, which represents a kind of uncertainty about the future (Venkatraman, 1989). Bauer (1960) believed that any purchase is risky, and consumers will have uncertain consequences after purchasing products, which consumers may not expect to see. Cui (2007) explained that perceived risk in the network refers to the uncertainty and loss perceived subjectively by buyers over online shopping. Gao (2004) emphasized that perceived risk is the main obstacle in consumers' purchasing decision-making process, and directly affect consumers' purchasing decisions and behaviors. Vellido and Meehan (2000) pointed out that in online shopping, the higher consumers' perceived risk is, the lower their purchase intention will be, and the less they will produce purchase behavior. Zhou (2011) believed that the higher the consumer's perceived uncertainty, the higher the perceived risk and the lower the consumer's purchase intention. Cui (2019) found in the network environment, the six dimensions of perceived risk, including product risk, financial risk, social risk, psychological risk, service risk and system risk, all had negative influences on 
consumers' impulse buying behavior to varying degrees. Based on above discussion, we propose the following hypotheses:

H5: Perceived risk has a significant negative impact on consumers' impulse buying decision.

\subsection{The Effect of Price Promotion on Perceived Risk}

Price promotion is an important means of promotion for merchants, which increase sales volume and create profits in a short time. Compared with traditional online shopping, the most important reason why more and more consumers tend to buy goods through network live streaming is that it usually adopts the way of time-limited kill with greater price discount to promote sales. Since the severity of currency loss marked by price is positively correlated with consumers' perceived risk, under the premise of a certain probability of loss, the lower the commodity price is, the smaller the consumers' perceived risk is. Wang et al. (2014) found that price discounts have a negative impact on consumers' perceived risk. Therefore, price promotion will weaken consumers' perceived risk in the context of live streaming e-commerce. Based on this, this paper proposes the following hypotheses:

H6: Price promotion has a significant negative impact on consumers' perceived risk.

\subsection{The Effect of Time Pressure on Perceived Risk}

According to the Construal Level Theory, a person's reaction to an event depends on the mental representation of the event (Liberman \& Sagristano, 2002). Psychological distance determines the degree of abstraction of people's mental representation of things (Nussbanum, Trope, \& Liberman, 2003) Psychological distance could be represented as temporal distance, spatial distance and social distance (Nussbanum et al., 2003). When individuals perceive a large psychological distance from the object, they are more willing to perceive and understand the object from the core, abstract and other perspectives, which is a high level of interpretation. When individuals perceive a small psychological distance from the object, they are more willing to perceive and understand things from the perspective of surface and specific external characteristics, which is a low level of interpretation (Liu et al., 2012). In the promotion situation, consumers may perceive greater time pressure, so they will perceive a close psychological distance between them and the goods. In this case, consumers might be more likely to be affected by the superficial information of the goods in their purchase decisions, instead of making a rational and comprehensive evaluation of the goods. Under this situation, the perceived risk of the consumer would be lower than in the case of low time pressure, so the promotion time limit may reduce the perceived risk of the consumer. In addition, in a promotional activity, if consumers do not make a purchase decision within the promotional deadline, there will be a certain opportunity cost. Lu et al. (2013) revealed that in the promotion activity, both the promotion time limit and the opportunity cost perception would make consumers exaggerate perceived benefits and ignore perceived risks. Hence, we propose the following hypotheses:

H7a: Promotion time limit has a significant negative impact on consumers' perceived risk;

H7b: Perceived opportunity cost has a significant negative impact on consumers' perceived risk.

\subsection{The Effect of Interpersonal Interaction on Perceived Risk}

In online shopping, there is a negative correlation between online interaction and consumers' perceived risk (Zhang, 2009). Mitchell and Boustani (1994) revealed that in the five stages of consumers' purchasing process, consumers have different levels of perceived risk. In the need recognition stage, because consumers have not determined their own needs and cannot solve their own demand problems, the perceived risk is constantly increasing; In the information search stage, consumers have determined the desired products and begin to collect product information. At this time, with the increase of product information, perceived risk begins to decrease gradually. In the alternative evaluation stage, consumers have mastered the relevant information and knowledge of products, so the perceived risk will continue to decrease; In the process of purchasing decision, perceived risk increases slightly, because consumers are not sure whether their decision is correct, their perceived risk still exist. In the post-purchase stage, perceived risk of customers is different. If consumers are satisfied with their purchase decision, the risk will continue to decrease; while if they are not satisfied, the perceived risk may increase (Mitchell \& Boustani, 1994). It can be seen that information search can reduce information asymmetry and uncertainty, and thus reduce consumers' perceived risk. In live streaming e-commerce, interpersonal interaction is the main way for consumers to obtain product information. By interacting with streamers, consumers could learn more about the details and functions of products. And by interacting with other consumers who have purchasing experience, consumers could make better purchasing decisions and improve the quality of their decisions. Based on this discussion, we propose the following hypotheses: 
H8a: The interaction between consumers and streamers has a significant negative impact on consumers' perceived risk;

H8b: Interaction between consumers has a significant negative impact on consumers' perceived risk.

\subsection{The Effect of Visual Appeal on Perceived Risk}

Kim and Lennon (2010) found that the more consumers' perceived information and the better their perceived quality, the lower the consumer's perceived risk. The biggest difference between live e-commerce and traditional e-commerce is in the way the products are presented: traditional e-commerce uses text, pictures and other flat information to introduce products, and it is impossible to intuitively feel the details and quality of the product, while live streaming e-commerce has real videos dynamics which can create a virtual sense of touch for consumers and make consumers feel on the spot. Live streaming e-commerce could show consumers the details of products through clothing try-on and product trials. In addition, the streamer's explanation of the product may enable consumers to have a clear understanding of the quality and function of the product, thereby reducing the consumer's perceived risk. Hence, we propose hypotheses

H9: Visual Appeal has a significant negative impact on consumers' perceived risk.

\subsection{The Mediating Role of Perceived Risk}

Based on the above discussion, various influencing factors may have a negative impact on perceived risk, and perceived risk has a significant negative impact on impulse buying behavior. Therefore, this research proposes that price promotion, time pressure (promotional time limit, perceived opportunity cost), interpersonal interaction (consumer-streamer interaction, consumer-consumer interaction) and visual appeal may indirectly affect consumers' impulse buying decision by affecting consumers' perceived risk. Hence, we propose the following hypotheses:

H10: There will be a mediating effect of perceived risk between price promotion and impulse buying decision.

H11: There will be a mediating effect of perceived risk between attitude promotional time limit and impulse buying decision.

H12: There will be a mediating effect of perceived risk between perceived opportunity cost and impulse buying decision.

H13: There will be a mediating effect of perceived risk between consumer-streamer interaction and impulse buying decision.

H14: There will be a mediating effect of perceived risk between consumer-consumer interaction and impulse buying decision.

H15: There will be a mediating effect of perceived risk between visual appeal and impulse buying decision.

In summary, based on S-O-R model, the factors influencing the Chinese consumers' impulse buying decision of live streaming e-commerce could be hypothesized as follows (Figure 2). The independent variables are four factors including price promotion, time pressure (promotional time limit, perceived opportunity cost), interpersonal interaction (consumer-streamer interaction, consumer-consumer interaction) and visual appeal, while dependent variable is impulse buying decision, and the mediating variable is consumers' perceived risk.

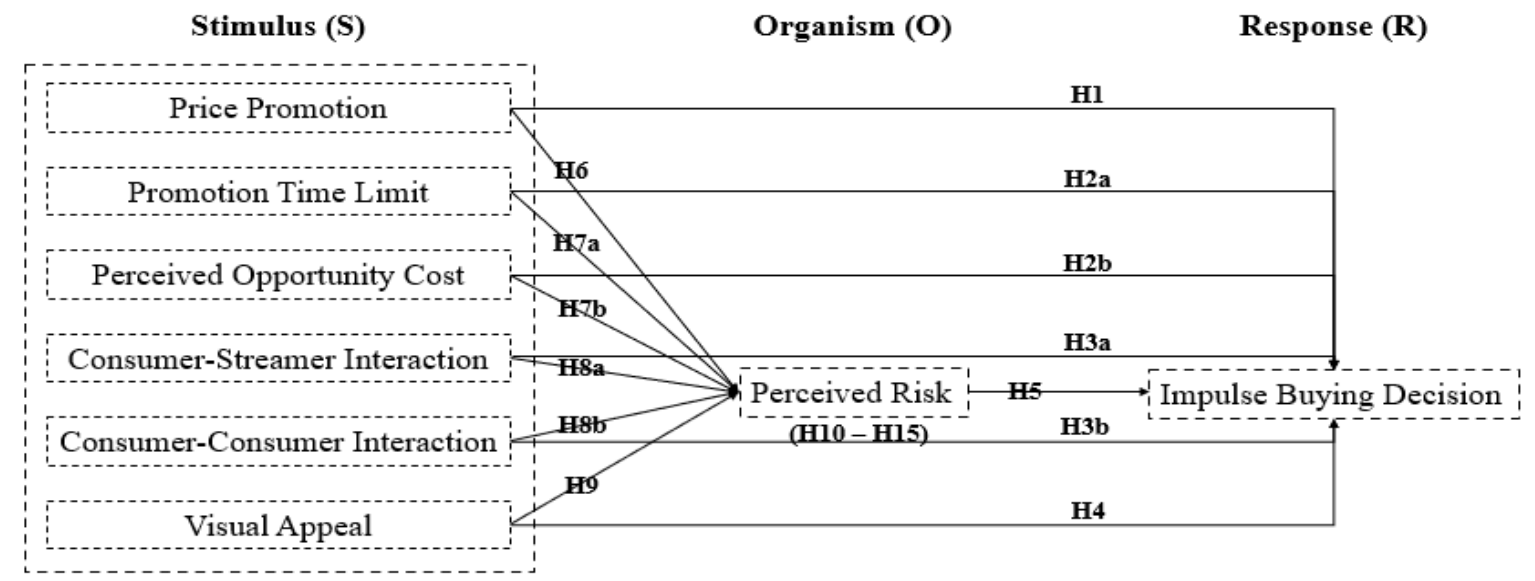

Figure 2. Conceptual Framework 


\section{Research Methodology}

\subsection{Sample and Data Collection}

This research is a quantitative design using online self-administration questionnaire to collect data with convenience sampling approach from Chinese users who has live streaming shopping experience in social commerce platform Taobao.com. within the past 1 year in Kunming, City. Taobao.com, the largest e-commerce platform in China, has added "live streaming shopping" functions to their websites. Since the size of the target population of this study is difficult to define in actual size, the formula of Cochran (1977) will be chosen for calculating the sample size used in the quantitative analysis. Hence, the actual sample size was 385 . Among the collected questionnaires, 27 were invalid resulting in 477 usable questionnaires finally.

\subsection{Measurement Scales}

Our questionnaire is divided into three parts. The first part allows the author to identify whether the respondent is eligible to take part in this research (screening questions); the second part contains some multi-choice questions which are shown to collect basic personal information. The third part elaborated each variable that would be tested in the survey. In measuring the constructs, five-point Likert scale anchored by: $1=$ strongly disagree, $2=$ disagree, $3=$ neither agree nor disagree, $4=$ agree and $5=$ strongly agree was used in the questionnaire with adoption from different sources of the existing literature. Table 1 shows the details of the measurement items in the research.

Table 1. Source of Measurement Item in Questionnaire

\begin{tabular}{|c|c|c|}
\hline Variable & Measurement Items & Source \\
\hline \multirow{3}{*}{$\begin{array}{l}\text { Price Promotion } \\
\qquad(\mathrm{PP})\end{array}$} & I am easily attracted by price promotions. & \multirow{3}{*}{ Liu (2016) } \\
\hline & When it comes to price promotions, I cannot help buying & \\
\hline & The price promotion gave me a strong impulse to buy. & \\
\hline \multirow{3}{*}{$\begin{array}{l}\text { Promotion Time } \\
\text { Limit } \\
\text { (PTL) }\end{array}$} & I feel that streamers usually give a short promotional period. & \multirow{7}{*}{$\begin{array}{c}\text { Payne, } \\
\text { Bettman \& } \\
\text { Luce } \\
\text { (1996) }\end{array}$} \\
\hline & I feel like I have less time to decide whether to buy a sale or not. & \\
\hline & I have a feeling that the sales deadline for the seckill product will run out very soon. & \\
\hline \multirow{4}{*}{$\begin{array}{c}\text { Perceived } \\
\text { Opportunity Cost } \\
\text { (POC) }\end{array}$} & $\begin{array}{l}\text { I feel that the opportunity to buy a seckill product is fleeting and it is too bad not to } \\
\text { buy it }\end{array}$ & \\
\hline & $\begin{array}{l}\text { I feel like seckill products are so cheap that if I do not buy them, someone else will } \\
\text { snap them up }\end{array}$ & \\
\hline & $\begin{array}{l}\text { I feel like the product has a very short promotional time, and if I do not buy it, I'll } \\
\text { miss it. }\end{array}$ & \\
\hline & $\begin{array}{l}\text { I feel like the number of items on seckill is limited, and if I do not buy it, someone } \\
\text { else will snap it up. }\end{array}$ & \\
\hline \multirow{3}{*}{$\begin{array}{c}\text { Consumer-Streamer } \\
\text { Interaction } \\
\text { (CSI) }\end{array}$} & Streamer is very happy to communicate with me. & \multirow{6}{*}{$\begin{array}{l}\text { Zhao et al. } \\
\text { (2015) }\end{array}$} \\
\hline & Streamers give corresponding feedback to my inquiries. & \\
\hline & I get a lot of good advice from streamers & \\
\hline \multirow{3}{*}{$\begin{array}{l}\text { Consumer-Consumer } \\
\text { Interaction } \\
(\mathrm{CCI})\end{array}$} & I will share my shopping experience and feelings with other consumers. & \\
\hline & I can communicate with other consumers smoothly. & \\
\hline & What other consumers said about the product helped me make my purchase decision. & \\
\hline \multirow{4}{*}{ Visual Appeal (VA) } & Streamers make a clear presentation of the products for sale. & \multirow{4}{*}{$\begin{array}{l}\text { Mathwick } \\
\text { et al. (2001) }\end{array}$} \\
\hline & The way the streamers present the products is very attractive & \\
\hline & The overall visual effect of the live streaming room is very good & \\
\hline & I like the overall layout of the live streaming room. & \\
\hline \multirow{4}{*}{ Perceived Risk (PR) } & I am afraid the product is not as good as the streamer says. & \multirow{4}{*}{$\begin{array}{l}\text { Zhao et al. } \\
\text { (2015) }\end{array}$} \\
\hline & I am afraid after-sales service is not good. & \\
\hline & I always feel uneasy about buying goods in the live streaming room. & \\
\hline & I worry that the prices on offer in the studio are higher than in other similar markets. & \\
\hline
\end{tabular}


I did not plan it at all until I went into the live streaming room and decided to buy it.

Impulse Buying

Decision

(IBD)
I bought the product without thinking it through at all.

I was completely influenced by the mood of the moment when I made the purchase.

In the process of shopping, I have a strong desire to buy some goods that I would not

Beatty \&

Ferrell

(1998) have intended to buy.

\section{Research Analysis and Results}

\subsection{Demographic Profile}

As presented in the Table 2, there are obviously more female consumers than men, out of 477 respondents, there are 367 female consumers, accounting for $76.94 \%$ of the total. Most respondents are students with bachelor degree, aged between 19-30. The reason might be that students, compared with consumers of other occupations, have more disposable time to spend on online live streaming. Furthermore, most respondents spend between 2,000 and 4,000 a month on online purchase because of live streaming. Nearly $70 \%$ of respondents spend 10 and above hours on live streaming every week. The detailed descriptive statistics of the respondents are listed in Table 2.

Table 2. Demographic Profile of the Respondents

\begin{tabular}{|c|c|c|c|}
\hline \multicolumn{2}{|c|}{ Demographics Characteristics } & Frequency & $\%(\mathrm{n}=477)$ \\
\hline \multirow{2}{*}{ Gender } & Male & 110 & $23.06 \%$ \\
\hline & Female & 367 & $76.94 \%$ \\
\hline \multirow{5}{*}{ Age (years old) } & Under 18 & 65 & $13.63 \%$ \\
\hline & $19-30$ & 307 & $64.36 \%$ \\
\hline & $31-40$ & 52 & $10.90 \%$ \\
\hline & $41-50$ & 33 & $6.92 \%$ \\
\hline & Above 51 & 20 & $4.19 \%$ \\
\hline \multirow{5}{*}{ Education Level } & High school or less & 61 & $12.79 \%$ \\
\hline & Diploma & 112 & $23.48 \%$ \\
\hline & Bachelor's Degree & 233 & $48.85 \%$ \\
\hline & Master's Degree & 56 & $11.74 \%$ \\
\hline & Doctoral Degree & 15 & $3.14 \%$ \\
\hline \multirow{4}{*}{$\begin{array}{l}\text { Monthly Spending on Live } \\
\text { Streaming }\end{array}$} & $<2,000 \mathrm{RMB}$ & 107 & $22.43 \%$ \\
\hline & $2,001-4,000 \mathrm{RMB}$ & 271 & $56.81 \%$ \\
\hline & 4,001-6,000 Years & 73 & $15.30 \%$ \\
\hline & $>6,001 \mathrm{RMB}$ & 26 & $5.45 \%$ \\
\hline \multirow{4}{*}{ Occupation } & Student & 286 & $59.96 \%$ \\
\hline & Office worker & 131 & $27.46 \%$ \\
\hline & Self-employed & 29 & $6.08 \%$ \\
\hline & Others & 31 & $6.50 \%$ \\
\hline \multirow{5}{*}{ Weekly Watch Live Hours } & $<5$ Hours & 49 & $10.27 \%$ \\
\hline & 6-10 Hours & 99 & $20.75 \%$ \\
\hline & 11-15 Hours & 203 & $42.56 \%$ \\
\hline & 16-20 Hours & 91 & $19.08 \%$ \\
\hline & $>21$ Hours & 35 & $7.34 \%$ \\
\hline
\end{tabular}

\subsection{Reliability and Validity}

All the data were analyzed by creating structural and measurement models in AMOS software. Reliability was estimated by using composite reliability (CR) and Cronbach's Alpha, which measures the stability and equivalence of the construct (Hair et al., 2009). A value of composite reliability and Cronbach's Alpha greater than 0.7 is acceptable (Fornell \& Larcker, 1981). As Table 3 shows, the composite reliabilities and Cronbach's Alpha for all constructs exceed 0.7, which are acceptable reliabilities of the constructs. Construct validity was determined by the convergent and discriminant validities. Convergent validity was measured using the average 
variance exacted (AVE) (Hair et al., 2009). All the AVEs shown in Table 3 were above 0.72, which is greater than the recommended level of 0.5 . Thus, the convergent validity is satisfied. Discriminant validity indicates whether the construct is distinct from other constructs and is calculated by comparing the square root of the AVE of each construct to the correlations between the construct and all other constructs (Fornell and Larcker, 1981). As can be seen in Table 4, all the square roots of AVEs are higher than the correlation value of the factor and all other factors, which means the discriminant validity of each construct is acceptable.

Table 3. Results of Validity and Reliability Analysis

\begin{tabular}{|c|c|c|c|c|c|}
\hline Factors & Indicators & $\begin{array}{l}\text { Factor Loadings } \\
\qquad(>0.5)\end{array}$ & $\begin{array}{c}\text { AVE } \\
(>0.5)\end{array}$ & $\begin{array}{c}\mathrm{CR} \\
(>0.7)\end{array}$ & $\begin{array}{l}\text { Cronbach's Alpha } \\
\qquad(>0.7)\end{array}$ \\
\hline \multirow{3}{*}{$\begin{array}{l}\text { Price Promotion } \\
\text { (PP) }\end{array}$} & PP1 & 0.79 & \multirow{3}{*}{0.72} & \multirow{3}{*}{0.84} & \multirow{3}{*}{0.92} \\
\hline & PP2 & 0.83 & & & \\
\hline & PP3 & 0.78 & & & \\
\hline \multirow{3}{*}{$\begin{array}{l}\text { Promotion Time Limit } \\
\text { (PTL) }\end{array}$} & PTL1 & 0.81 & \multirow{3}{*}{0.83} & \multirow{3}{*}{0.91} & \multirow{3}{*}{0.93} \\
\hline & PTL2 & 0.78 & & & \\
\hline & PTL3 & 0.80 & & & \\
\hline \multirow{4}{*}{$\begin{array}{l}\text { Perceived Opportunity Cost } \\
\text { (POC) }\end{array}$} & POC1 & 0.81 & \multirow{4}{*}{0.85} & \multirow{4}{*}{0.95} & \multirow{4}{*}{0.96} \\
\hline & POC2 & 0.82 & & & \\
\hline & POC3 & 0.79 & & & \\
\hline & POC4 & 0.76 & & & \\
\hline \multirow{3}{*}{$\begin{array}{l}\text { Consumer-Streamer Interaction } \\
\text { (CSI) }\end{array}$} & CSI1 & 0.81 & \multirow{3}{*}{0.88} & \multirow{3}{*}{0.92} & \multirow{3}{*}{0.91} \\
\hline & $\mathrm{CSI} 2$ & 0.81 & & & \\
\hline & CSI3 & 0.82 & & & \\
\hline \multirow{3}{*}{$\begin{array}{l}\text { Consumer-Consumer Interaction } \\
\qquad(\mathrm{CCI})\end{array}$} & CCI1 & 0.86 & \multirow{3}{*}{0.89} & \multirow{3}{*}{0.96} & \multirow{3}{*}{0.84} \\
\hline & $\mathrm{CCI} 2$ & 0.88 & & & \\
\hline & $\mathrm{CCI} 3$ & 0.85 & & & \\
\hline \multirow{4}{*}{ Visual Appeal (VA) } & VA1 & 0.76 & \multirow{4}{*}{0.89} & \multirow{4}{*}{0.88} & \multirow{4}{*}{0.90} \\
\hline & VA2 & 0.75 & & & \\
\hline & VA3 & 0.74 & & & \\
\hline & VA4 & 0.78 & & & \\
\hline \multirow{4}{*}{ Perceived Risk (PR) } & PR1 & 0.83 & \multirow{4}{*}{0.93} & \multirow{4}{*}{0.86} & \multirow{4}{*}{0.89} \\
\hline & PR2 & 0.84 & & & \\
\hline & PR3 & 0.81 & & & \\
\hline & PR4 & 0.82 & & & \\
\hline \multirow{4}{*}{$\begin{array}{l}\text { Impulse Buying Decision } \\
\text { (IBD) }\end{array}$} & IBD1 & 0.83 & \multirow{4}{*}{0.85} & \multirow{4}{*}{0.91} & \multirow{4}{*}{0.93} \\
\hline & IBD2 & 0.86 & & & \\
\hline & IBD3 & 0.84 & & & \\
\hline & IBD4 & 0.82 & & & \\
\hline
\end{tabular}

Table 4. Discriminant Validity Fornell-Larcker Table

\begin{tabular}{|c|c|c|c|c|c|c|c|c|}
\hline Constructs & $\mathrm{PP}$ & PTL & POC & CSI & CCI & VA & PR & IBD \\
\hline PP & 0.87 & & & & & & & \\
\hline PTL & 0.42 & 0.86 & & & & & & \\
\hline POC & 0.13 & 0.48 & 0.89 & & & & & \\
\hline CSI & 0.21 & 0.42 & 0.33 & 0.93 & & & & \\
\hline CCI & 0.26 & 0.49 & 0.39 & 0.49 & 0.93 & & & \\
\hline VA & 0.32 & 0.52 & 0.31 & 0.38 & 0.46 & 0.94 & & \\
\hline PR & 0.36 & 0.47 & 0.35 & 0.34 & 0.31 & 0.49 & 0.94 & \\
\hline IBD & 0.38 & 0.42 & 0.38 & 0.35 & 0.27 & 0.37 & 0.44 & 0.88 \\
\hline
\end{tabular}




\subsection{Measurement and Structural Model Analysis}

A model is considered suitable if the covariance structure implied by the model is similar to the covariance structure of the sample data, as indicated by an acceptable value of goodness-of-fit index (GFI) (Cheung \& Rensvold, 2002). Firstly, the measurement model was verified and evaluated then the structural model analyzed and fitted. According to Kline (2011), fit statistics greater than or equal to 0.9 for GFI, CFI and NFI, greater or equal 0.80 for AGFI indicate a good model fit. In addition, the recommended value of $\chi 2 / \mathrm{df}$ is smaller than 3 and RMSEA values smaller than 0.05 , which is acceptable. The results of the indexes of model fitness are described in Table 5. All of these values exceed their common acceptable range, suggesting high construct reliability and convergent validity of the internal structure of research model.

Table 5. Fit Indices of Measurement and structural models

\begin{tabular}{ccccccc}
\hline Fit indices & $\chi 2 / \mathrm{df}$ & GFI & AGFI & CFI & NFI & RMSEA \\
\hline Recommended Values & $<3$ & $\geq 0.9$ & $\geq 0.8$ & $\geq 0.9$ & $\geq 0.9$ & $<0.05$ \\
Measurement Model & 1.15 & 0.93 & 0.91 & 0.92 & 0.95 & 0.03 \\
Structural Model & 1.16 & 0.92 & 0.93 & 0.93 & 0.94 & 0.04 \\
\hline
\end{tabular}

\subsection{Hypothesized Direct Relationship}

Table 6 showed the standardized path coefficient and path significance for each hypothesis. With regard to H1, it can be observed that a significant and positive correlation between price promotion $(\beta=0.548, \mathrm{p}<0.001)$ and customers impulse buying decision on live streaming, which means that $\mathrm{H} 1$ was fully supported. Concerning $\mathrm{H} 2 \mathrm{a}$ and $\mathrm{H} 2 \mathrm{~b}$, promotion time limit $(\beta=0.187, \mathrm{p}<0.001)$ and perceived opportunity cost $(\beta=0.251, \mathrm{p}<0.01)$ are significantly positive affect customers impulse buying decision, Thus, H2a and H2b were supported. Similarly, interpersonal interaction including consumer-streamer interaction $(\beta=0.179, \mathrm{p}<0.001)$ and consumer-consumer interaction $(\beta=0.136, p<0.001)$ were found have positive effect on customers impulse buying decision. Thus, supporting $\mathrm{H} 3 \mathrm{a}$ and $\mathrm{H} 3 \mathrm{~b}$. Regarding $\mathrm{H} 4$, a positive link existed between relationship visual appeal and consumer impulse buying decision $(\beta=0.484, \mathrm{p}<0.01)$, Hence, $\mathrm{H} 4$ was supported. In addition, our results show that perceived risk had a negative impact on customers impulse buying decision on live streaming $(\beta=-0.515$, $\mathrm{p}<0.001)$. Hence, H5 was supported. In line with our hypothesis, price promotion $(\beta=-0.436, p<0.001)$, perceived opportunity cost $(\beta=-0.186, \mathrm{p}<0.01)$, consumer-streamer interaction $(\beta=-0.159, \mathrm{p}<0.001)$, consumer-consumer interaction $(\beta=-0.326, p<0.01)$ and visual appeal $(\beta=-0.258, p<0.001)$ were found to generate a significant effect on perceived risk of customers $(\beta=.110, \mathrm{p}<.001)$ in a negative way; Thus, H6, H7b, $\mathrm{H} 8 \mathrm{a}, \mathrm{H} 8 \mathrm{~b}$ and $\mathrm{H} 9$ were all fully supported. However, when $\mathrm{H} 7 \mathrm{a}$ is examined, it is found that promotion time limit $(\beta=-0.193, p>0.05)$ had no impact on perceived risk of customers. Thus, H7a was rejected.

Table 6. Test Results of Research Hypothesis

\begin{tabular}{|c|c|c|c|c|c|}
\hline Hypothesis & Path & Path Coefficient ( $\beta$ ) & S.E. & $\mathrm{P}$ & Results \\
\hline H1 & $\mathrm{PP} \rightarrow \mathrm{IBD}$ & 0.548 & 0.035 & $* * *$ & Supported \\
\hline $\mathrm{H} 2 \mathrm{a}$ & $\mathrm{PTL} \rightarrow \mathrm{IBD}$ & 0.187 & 0.026 & $* * *$ & Supported \\
\hline $\mathrm{H} 2 \mathrm{~b}$ & $\mathrm{POC} \rightarrow \mathrm{IBD}$ & 0.251 & 0.036 & $* *$ & Supported \\
\hline $\mathrm{H} 3 \mathrm{a}$ & $\mathrm{CSI} \rightarrow \mathrm{IBD}$ & 0.179 & 0.052 & $* * *$ & Supported \\
\hline $\mathrm{H} 3 \mathrm{~b}$ & $\mathrm{CCI} \rightarrow \mathrm{IBD}$ & 0.136 & 0.057 & $* * *$ & Supported \\
\hline $\mathrm{H} 4$ & $\mathrm{VA} \rightarrow \mathrm{IBD}$ & 0.484 & 0.041 & $* *$ & Supported \\
\hline H5 & $\mathrm{PR} \rightarrow \mathrm{IBD}$ & -0.515 & 0.034 & $* * *$ & Supported \\
\hline H6 & $\mathrm{PP} \rightarrow \mathrm{PR}$ & -0.436 & 0.046 & $* * *$ & Supported \\
\hline $\mathrm{H} 7 \mathrm{a}$ & $\mathrm{PTL} \rightarrow \mathrm{PR}$ & -0.193 & 0.053 & 0.069 & Rejected \\
\hline $\mathrm{H} 7 \mathrm{~b}$ & $\mathrm{POC} \rightarrow \mathrm{PR}$ & -0.186 & 0.045 & $* * *$ & Supported \\
\hline $\mathrm{H} 8 \mathrm{a}$ & $\mathrm{CSI} \rightarrow \mathrm{PR}$ & -0.159 & 0.038 & $* * *$ & Supported \\
\hline $\mathrm{H} 8 \mathrm{~b}$ & $\mathrm{CCI} \rightarrow \mathrm{PR}$ & -0.326 & 0.024 & $* *$ & Supported \\
\hline H9 & $\mathrm{VA} \rightarrow \mathrm{PR}$ & -0.258 & 0.056 & $* * *$ & Supported \\
\hline
\end{tabular}

$* \mathrm{p}<.05 ; * * \mathrm{p}<.01 ; * * * \mathrm{p}<.001$

\subsection{Mediation Analysis}

The findings of Table 7 exhibit the mediating influence of perceived risk in the relationship of independent variables, such as PP, PTL, POC, CSI, CCI and VA, as well as dependent variable impulse buying decision. The 
outcomes of mediation have been measured through bootstrapping method which could be regarded as the most accurate way to test mediation and other intervening effects (Biesanz, Falk, \& Savalei, 2010)). 5000 samples were set to judge whether there was a mediating effect under the $95 \%$ bias-corrected bootstrapping confidence interval. If zero was not occur between the upper and lower limits of the bias-corrected confidence interval, the mediating effect was established (Hayes, 2009). As can be seen from Table 6, the presence of total effects means that there are indirect effects. The findings of Table 7 establish that the mediating variable perceived risk has had a mediation between each independent factor and the impulse buying decision of Chinese customers on live streaming except promotion time limit this factor. Consequently, H10, H12, H13, H14 and H15 are all supported while H11 was rejected.

Table 7. Test Results of Mediating Effect

\begin{tabular}{|c|c|c|c|c|c|}
\hline \multirow[t]{2}{*}{ Hypotheses } & \multirow[t]{2}{*}{ Paths } & \multirow{2}{*}{$\begin{array}{c}\text { Point } \\
\text { Estimation }\end{array}$} & \multicolumn{2}{|c|}{$\begin{array}{c}\text { Bootstrapping 95\% Confidence } \\
\text { Interval }\end{array}$} & \multirow{2}{*}{$\begin{array}{l}\text { Whether Mediating } \\
\text { Effect or Not? }\end{array}$} \\
\hline & & & Lower & Upper & \\
\hline \multicolumn{2}{|c|}{ Total Mediation Effect } & 0.856 & 0.398 & 0.752 & YES \\
\hline H10 & $\mathrm{PP} \rightarrow \mathrm{PR} \rightarrow \mathrm{IBD}$ & 0.239 & 0.083 & 0.324 & YES \\
\hline H11 & $\mathrm{PTL} \rightarrow \mathrm{PR} \rightarrow \mathrm{IBD}$ & 0.151 & -0.035 & 0.206 & NO \\
\hline H12 & $\mathrm{POC} \rightarrow \mathrm{PR} \rightarrow \mathrm{IBD}$ & 0.201 & 0.012 & 0.025 & YES \\
\hline H13 & $\mathrm{CSI} \rightarrow \mathrm{PR} \rightarrow \mathrm{IBD}$ & 0.104 & 0.007 & 0.101 & YES \\
\hline H14 & $\mathrm{CCI} \rightarrow \mathrm{PR} \rightarrow \mathrm{IBD}$ & 0.143 & 0.102 & 0.256 & YES \\
\hline H15 & $\mathrm{VA} \rightarrow \mathrm{PR} \rightarrow \mathrm{IBD}$ & 0.018 & 0.119 & 0.319 & YES \\
\hline
\end{tabular}

\section{Discussion and Conclusions}

\subsection{Discussion}

This study examines the effects of price promotion, time pressure (promotion time limit, perceived opportunity cost), interpersonal interaction (consumer-streamer interaction, consumer-consumer interaction) and visual appeal on impulse buying behavior of Chinese consumers in live streaming ecommerce. Based on the effective questionnaire collected from 477 Chinese users who has live streaming shopping experience in social commerce platform Taobao.com. within the past 1 year in Kunming City. the model proposed by this research is verified, and the following conclusions are further obtained:

First of all, the results show that all the influencing factors including price promotion, time pressure (promotion time limit, perceived opportunity cost), interpersonal interaction (consumer-streamer interaction, consumer-consumer interaction) and visual appeal have a direct positive impact on consumers' impulse buying decision, among which the weight of price promotion and visual appeal is significantly higher than other factors. This means that the price discount and visual stimulation in the purchase process are more likely to stimulate the impulse purchase decision of consumers. In the environment of live streaming e-commerce, compared with other influencing factors, price promotion has a greater impact on impulse buying. This may be because consumers are more sensitive to price discounts, and the reduction of commodity prices could stimulate consumers' desire to buy more. At the same time, the display of products by streamers (such as cosmetics trial, clothing fitting, etc.) will bring a visual impact to consumers, which also stimulate the demand of consumers and increase their purchasing behavior. Besides, due to consumers' impulsive characteristics, self-inconsistency and other characteristics, during the short promotional period, consumers will have time pressure, and thus may have impulse buying behavior. In addition, the interaction between consumers, streamers and consumers also could improve consumers' emotions, make them feel happy, and then increase their purchasing behavior.

Second, the results show that the promotion, the perception of opportunity cost, the interpersonal interaction (the interaction between consumers and streamers, the interaction between consumers), and the visual appeal all have a significant negative impact on consumers' perceived risk. However, for time limit of time pressure, our research hypothesis that promotion time limit has a significant negative effect on consumers' perceived risk has not been verified. The reason might be that it is difficult for consumers to understand all the information of the products during the short promotional period of the merchants. The uncertainty of information will stimulate consumers to make an immediate purchase decision in a relatively short period of time, thus perceiving a higher purchase risk.

Third, this study verifies that perceived risk has a significant negative impact on consumers' impulse buying decisions. Therefore, in order to improve consumers' purchasing decisions and increase product sales, merchants 
could take effective measures to reduce consumers' perceived risks, such as reducing prices, providing service guarantees, and introducing product information in detail, etc.

Finally, we also found that perceived risk plays a mediation effect on the relationship between price promotion, perceived opportunity cost, interpersonal interaction, visual appeal and impulse buying decision. However, perceived risk did not play a mediating role in the effect of promotion time limit on impulse buying decision. When the price of products is preferential, the consumers' perceived value and perceived benefits will increase, and the perceived risk will decrease, thus stimulating the desire of consumers to purchase. At the same time, the interaction between consumers and streamers and consumers could enhance the sense of trust between them. The introduction of products by streamers and feedbacks from other consumers could reduce consumers' perceived risks and thus enhance their purchase decision. In the limited promotion time, consumers will perceive greater opportunity cost if they give up the purchase or delay the decision. In order to avoid the loss of opportunity, consumers will make purchase decision. In addition, because streamers display and explain details and functions of products, consumers could fully perceive the quality of products, reduce their perceived risks, and thus stimulate consumers' buying decision.

\subsection{Implications}

In terms of theoretical implication, this study abstracts the main influencing factors of live streaming e-commerce consumers' impulse buying decision. It not only analyzes the influence of each influencing factor on impulse buying decision and its influencing mechanism, but also compares the weight of each influencing factor. Our findings supplement the theories related to impulse buying and have a certain theoretical contribution to the research in the field of live streaming e-commerce.

The findings of this paper also provide practical and beneficial management inspiration for live streaming businesses such as merchants, marketers and managers. First of all, live streaming e-commerce marketers need to develop reasonable price promotion schemes and strategies. Promotion is a common marketing method used by merchants, which prompt consumers to have immediate purchase behavior. Among various promotion activities, price promotion is an important factor affecting consumers' impulse purchase decision. Merchants could properly carry out low-price limited-time seckill and limited buying promotions. Price promotion also make consumers' perceived benefits higher than perceived risks. In the case of limited time, consumers may perceive the loss of opportunities if they give up the purchase or delay the decision. Therefore, making reasonable price promotion scheme could enhance consumers' impulse purchase decision. However, in the process of promotion, managers must grasp the intensity of price promotion, because once consumers are accustomed to buying products at a lower price in the live streaming room, when the product is restored to the original price, consumers will feel it difficult to accept the original price of the product, which might lead to no repurchase, thus affecting the profits of the merchants.

Additionally, live streaming e-commerce providers should pay attention to providing consumers with good visual experience. Visual appeal significantly increases consumers' impulse purchase decision. First, marketers should pay attention to the overall style of the live streaming room. The layout should be neat and clear, and the color collocation should be warm and comfortable. A good consumption environment will bring consumers a pleasant feeling, and then enhance consumers' desire to buy. Besides, streamers should fully show the quality and details of commodities to consumers (such as clothing trying on, cosmetics trial, etc.), stimulate the demand of consumers through strong visual impact, and encourage consumers to have impulse purchase desire. Thirdly, streamers should explain the functions of the products in detail, deepen consumers' understanding of the products, reduce consumers' perceived risks, and make consumers feel at ease to purchase.

Furthermore, live streaming e-commerce marketers need to strengthen interpersonal interaction. In interpersonal interaction, both the interaction between consumers and streamers and the interaction between consumers will affect consumers' impulse purchase decision. First, during the live streaming, streamers should actively interact with consumers, activate the atmosphere in the live streaming room, give detailed and accurate answers to consumers' questions, and enhance consumers' trust in them. Second, some interesting activities (such as lottery, etc.) can be properly carried out to create an interactive atmosphere and increase the fun of the live streaming room. Finally, marketers could create a fan base (such as WeChat fan base, taobao fan base, etc.), by chat, the red envelope in the fan base, etc., not only could increase the active fans, but also can deepen the interaction between consumers and the streamers, between consumers and consumers, which would help streamers and consumers to establish a close interpersonal network, and enhance the intimacy between fans and streamers.

Finally, live streaming e-commerce providers should pay attention to the impact of perceived risk on impulse buying decision, so as to reduce consumers' purchasing risk. Merchants should attach importance on the impact 
of perceived risk on impulse buying and take measures to reduce consumers' purchasing risk. In addition to the price promotion in this research, factors such as time pressure, interpersonal interaction and visual appeal also could reduce perceived risk, marketers could also through the provision of related services to ensure (such as: freight risks, product quality assurance, 7 days no reason to return, etc.) to reduce consumer's perceived risk, and enhance their purchase desire, promote deals agreed upon between the seller and the buyer.

\subsection{Limitations and Recommendations for Further Research}

There are some limitations. The first limitation of the study lies in samples. Live streaming e-commerce is a wide field. This research only selects the consumers with online live shopping experience in Taobao live streaming, and does not carry out a survey on the consumers of other online live shopping platforms such as Jindong. Com, red book, etc. In the future, researchers can further expand the survey scope and increase the sample size. Secondly, this research studies the impact of price promotion, time pressure, interpersonal interaction and visual appeal only on consumers' impulse buying decision, using perceived risk as the mediating variable. In the future, researchers could make further investigation on other influencing factors such as attitude towards streaming services, personality with streaming services or product-related factors of live streaming e-commerce consumers. Thirdly, besides S-O-R model theory we used in the present study, a few other relevant theories such as satisfaction theory, motivation theory could be applied in the future studies. Finally, in a future study, the researchers could find out why perceived risk does not play a mediating role in the effect of promotion time limits on impulse buying decisions. Factors leading to consumer disagree in this questionnaire should also be investigated in future studies to better understand the causes of consumers disagree with live streaming, so as to effectively improve the services of live streaming operators and merchants.

\section{References}

Aminilari, M., \& Pakath, R. (2005). Searching for information in a time-pressured setting: experiences with a Text-based and an image-based decision support system. Journal of Decision Support Systems, 41(1), 37-68. https://doi.org/10.1016/j.dss.2004.02.005

Ariely, D., \& Zakay, D. (2001). A timely account of the role of duration in decision making. Acta Psychologica, 108(2), 187-207. https://doi.org/10.1016/S0001-6918(01)00034-8

Bauer, R. A. (1960). A consumer behavior as risk taking in dynamic marketing for a changing world (pp. 389-398). Proceedings of the $43^{\text {rd }}$ conference of the American marketing as sociation.

Beatty, S. E., \& Ferrell, M. E. (1998). Impulse Buying: Modeling its Precursors. Journal of Retailing, 74(2), 169-191. https://doi.org/10.1016/S0022-4359(99)80092-X

Biesanz, J. C., Falk C. F., \& Savalei, V. (2010) Assessing Mediational Models: Testing and interval estimation for indirect effects. Multivariate Behavioral Research, 45(4), 661-701. https://doi.org/10.1080/00273171.2010.498292.

Cangelosi, V. E., \& Dill, W. R. (1964). Organizational Learning: Observations Towards a Theory. Journal of Administrative Science Quarterly, 10(2), 175-203. https://doi.org/10.2307/2391412

Chen, Y., He, Y. S., \& Jin, S. (2018). Does a community atmosphere promote impulsive buying by members? Chongqing: Economics and Business Administration of Chongqing University.

Cheung, G. W., \& Resold, R. B. (2002). Evaluating goodness-of-fit indexes for testing measurement invariance. Structural Equation Modeling: A Multidisciplinary Journal, 9(2), 233-255. https://doi.org/10.1207/S15328007SEM0902_5

Cochran, G. W. (1977). Sampling Techniques (3rd ed.). New York, NY: John Wiley \& Sons.

Cui, J. F. (2019). The Impact of Perceived Risk on Online Impulse Buying by Consumers. Journal of Social Science Front, 286(4), 263-267.

Cui, Y. H. (2007). The application of perception risk theory in online shopping. International Journal of Electronic Commerce, 11(3), 75-79.

Dawson, S., \& Kim, M. (2010). Cues on apparel web sites that trigger impulse purchases. International Journal of Fashion Marketing and management, 14(2), 230-246. https://doi.org/10.1108/13612021011046084

Donovan, R. J., \& Rossiter, J. R. (1982). Store atmosphere: An environmental psychology approach. Journal of Retailing, 58(1), 34-57.

Fajar, D., Ketut, I., \& Maulita, N. N. P. (2020). Impact of shopping emotion towards impulse buying in e-commerce platform. Jurnal Manajemen dan Pemasaran Jasa, 13(1), 47-64. 
https://doi.org/10.25105/jmpj.v13i1.6123

Fornell, C., \& Larcker, D. F. (1981). Evaluating structural equation models with unobservable variables and measurement error. Journal of Marketing Research, 18(1), 39-50. https://doi.org/10.2307/3151312

Gao, H. X. (2004). Research on the application of perceived risk to consumer purchasing decisions. Journal of Business Research, (1), 94-96.

Hayes, A. F. (2009). Beyond Baron and Kenny: Statistical mediation analysis in the new millennium. Communication monographs, 76(4), 408-420. https://doi.org/10.1080/03637750903310360

He, A. Z., \& Gong, W. C. (2010). Research on the effect of online shopping experience on customer behavior tendency. Journal of East China Economic Management, 3, 112-116.

Huang, Z. X. (2018). Comparison between social e-commerce and traditional e-commerce: A case study of Pinduoduo.com and Taobao. Journal of Economic and Trade Practice, (23), 196-197.

Jiang, S., Zhao, H. X., \& Meng, L. (2014). Study on B2C online shopping interaction and consumers' impulsive purchasing behavior. Journal of Exploration of Economic Issue, 5, 64-73.

Kim, H., \& Lennon, S. J. (2010). E-atmosphere, emotional, cognitive, and behavioral responses. Journal of Fashion Marketing and Management, 14(3), 412-428. https://doi.org/10.1108/13612021011061861

Kline, R. B. (2011). Principles and practice of structural equation modeling (3rd ed.). New York, NY: The Guilford Press.

Krishna, A. (2012). An integrative review of sensory marketing: Engaging the senses to affect perception, judgment and behavior. Journal of Consumer Psychology, 22(3). 332-351. https://doi.org/10.1016/j.jcps.2011.08.003

Larose, R. (2001). On the Negative Effects of E-Commerce: A Socio-cognitive Exploration of Unregulated on-line Buying. Journal of Computer Mediated Communication, 6(3). 13-35. https://doi.org/10.1111/j.1083-6101.2001.tb00120.x

Li, D. J., Dai, F. L., \& Zhai, Y. M. (2018). Research on online impulse buying behavior of consumers based on S-O-R model. Journal of Anhui University of Technology: Social Science Edition, 35(4), 73-39.

Li, H. M., \& Cui, Y. Q. (2010). Research on the influence factors of consumer behavior based on context theory. Journal of Business Research, 3, 163-166.

Li, X. X., Yu, Y. B., \& Liu, Z. Z. (2018). Study on the relationship between price promotion and impulse purchase of customers. Journal of Northeastern University (Social Science Edition), 108(2), 33-39.

Liberman, N., Sagristano, M. D., \& Trope, Y. (2002). The effect of temporal distance on level of mental construal. Journal of Experimental Social Psychology, 38, 523-534. https://doi.org/10.1016/S0022-1031(02)00535-8

Liu, H. Y., Li, A. M., \& Wang, H. Z. (2012). The influence of different promotion methods on product purchase decision: A study from the perspective of Construal Level Theory. Journal of Psychology, 48(4), 110-1113.

Liu, J. P., \& Li, H. F. (2008). Decision Strategies and Decision Theory under Time Pressure. Journal of Henan University: Social Science, 48(6), 73-78.

Liu, J. D. (2013). Visual marketing and its evolution. Journal of Economic research Guide, (3), 232-234.

Liu, Y., Li, H. X., \& Hu, F. (2013). Website attributes in urging online impulse purchase: An empirical investigation on consumer perceptions. Decision Support Systems, 55(3), 829-837.

Liu, Z. Z. (2016). Study on the influence of price promotion on consumers' impulsive purchasing behavior. Dissertation. Liaoning: Liaoning University

Louis, Y. S., Lin, S. W., \& Hsu, L. Y. (2016). Motivation for Online Impulse Buying: A Two-Factor Theory Perspective. International Journal of Information Management, 36(5), 759-772. https://doi.org/10.1016/j.ijinfomgt.2016.04.012

Lu, C. B., Qin, Q. X., \& Lin, Y. Y. (2013). The Cognitive Mechanism of Consumers' Purchase Decision in Fake Promotions: An Empirical Study Based on Time Pressure and Overconfidence. Journal of Nankai Management Review, 16(2), 92-103.

Mathwick, C., Malhotra, N., \& Rigdon, E. (2001). Experiential value: conceptualization, measurement and application in the catalog and internet shopping environment. Journal of Retailing, 77(1), 39-56. 
https://doi.org/10.1016/S0022-4359(00)00045-2

Mehrabian, A., \& Russell, J. A. (1974). An approach to environmental psychology. Boston: The Massachusetts Institute of Technology.

Mitchell, V. W., \& Boustani, P. A. (1994). A preliminary investigation into pre-and post-purchase risk perception and reduction. European Journal of Marketing, 28(1), 56-71.

Nasreen, K., Lai, H. H., \& Tan, B. C. (2015). Impulse Buying Behavior of Generation Y in Fashion Retail. International Journal of Business \& Management, 11(1), 144-151. https://doi.org/10.5539/ijbm.v11n1p144

Nussbaum, S., Trope, Y., \& Liberman, N. (2003). Creeping dispositionism: The temporal dynamics of behavior prediction. Journal of Personality and Social Psychology, 84, 485-497. https://doi.org/10.1037/0022-3514.84.3.485

Parsad, C. (2020). Comparing between product-specific and general impulse buying tendency: Does shoppers' personality influence their impulse buying tendency? Asian Academy of Management Journal, 24(2), 41-61. https://doi.org/ 10.21315/aamj2019.24.2.3

Payne, J. W., Bettman, J. R., \& Luce, M. F. (1996). When time is money: decision behavior under opportunity-cost time pressure. Journal of Organizational Behavior \& Human Decision Processes, 66(2). 131-152. https://doi.org/ 10.1006/obhd.1996.0044

Peck. (2003). To Have and to Hold: The influence of Haptic Information on Product Judgement. Journal of Marketing, 67, 35-48. https://doi.org/10.1509/jmkg.67.2.35.18612

Rieskamp, J., \& Hoffrage, U. (2008). Inferences under time pressure: How opportunity costs affect strategy selection. Acta Psychologica, 127(2), 258-276. https://doi.org/10.1016/j.actpsy.2007.05.004

Rook, D. W. (1987). Buying Impulse. Journal of Consumer Research, 14(2), 189-199.

Seema, S., Richa, G., Vikas, G., \& Anita, V. (2019). Impact of Digitization on Impulse Buying - What Makes the Customer Bite the Bait. International Journal of Innovative Technology and Exploring Engineering, 8(7), 2948-2952.

Shen, Y., \& Zhao, H. M. (2018). Consumer impulsive buying behavior analysis based on the theory of the situation - in the case of Taobao live seconds kill. Journal of Operation and Management, 410(8), 126-132.

Study on the effect and influence mechanism of different atmospheric components. Journal of Business Economics and Management, 318(4), 60-71.

Svenson, O., \& Maule, J. (1993). Time pressure and stress in human and decision making. New York: Plenum Press.

Umair A., Peng, H., Muhammad, K. K., Chen, Y., \& Zubair, A. (2018). Factors Affecting Online Impulse Buying: Evidence from Chinese Social Commerce Environment. Sustainability, 10(2). 352. https://doi.org/10.3390/su10020352

Vellido, A., \& Meehan, L. K. (2000). Quantitative Characterization and Prediction of Online Purchasing Behavior: A Latent Variable Approach. International Journal of Electronic Commerce, 4(4), 83-104. https://doi.org/10.1080/10864415.2000.11518380

Venkatraman, M. (1989). Involvement and Risk. Psychology and Marketing, 6(3). 229-247. https://doi.org/10.1002/mar.4220060306

Wang, D. W., \& Liu, Y. F. (2008). The Influence of Attribution Style and Time Pressure on Buying Decision. Journal of Psychological Science, 31(4), 905-908.

Wang, Z. Z., Yao, Q., \& Ye, Y. (2014). Research on the effect of price discount and number of buyers on consumers' impulse buying intention in online group buying scenario. Journal of Management Engineering, 28(4), 37-47.

Weinberg, P., \& Gottwald, W. (1982). Impulsive Consumer Buying as a Result of Emotions. Journal of Business Research, 10(1), 43-57. https://doi.org/10.1016/0148-2963(82)90016-9

Wu, L. J. (2012). Based on S - O - R model of apparel online purchase intention theory framework. Modern Science and Technology of Silk, 27(5), 190-194.

Wu, W. C., \& Huan, T. C. (2010). The Effect of Purchasing Situation and Conformity Behavior on Young Students' Impulse Buying. African Journal of Business Management, 16, 3530-3540. 
Xie, X. X. (2015). The effect of expected regret on impulsive buying tendency of tourists under different time pressures: A study based on the theory of regulatory orientation. Dissertation. Jilin: Northeast Normal University.

Xiong, G. Q. (2017). Research on the influencing factors of consumers' purchasing intention in impulsive online shopping. Journal of Business Economics Research, 11, 35-38.

Yang, H., \& Lee, H. (2018). Exploring user acceptance of streaming media devices: An extended perspective of flow theory. Information Systems and e-Business Management, 16(1), 1-27.

Yang, K., \& Lu, W. W. (2013). Analysis of consumer impulse purchasing behavior based on network environment. Journal of Modern Management Science, 8, 102-104.

Yang, L. (2009). The influence of online store atmosphere on consumers' purchasing intention. Dissertation. Chongqing: Economics and Business Administration of Chongqing University.

Yang, Q., Lv, J. J., \& Shen, Y. C. (2017). Research on the Impact of WeChat Video Product Display on Consumers' Impulsive Purchases: virtual haptics perspective. Journal of Management and Administration, 12, 137-141.

Yin, C. (2013). Research on the Impact of Online Promotion on Impulsive Buying Behavior of Consumers. Dissertation. Shandong: Shandong University.

Zhang, P., Xie, M. D., \& Zhao, D. Y. (2019). The influence of social network on consumers' impulse purchase: A model and empirical analysis. Journal Business Economics Research, 767(4), 68-71.

Zhang, S., \& Wei, M. X. (2019). The Formation of Online Impulse Buying Desire: An Empirical Study Based on Social Commerce. Journal of Jinan (Philosophy and Social Sciences Edition), 41(5), 17-29.

Zhang, X. C. (2009). Research on perceived risk in C2C model based on the perspective of interactivity. Journal of Value Engineering, 9(9), 104-108.

Zhao, H. X., Cai, Z. H., \& He, S. (2014). Research on Online Product Display, Online Interaction and Impulsive Buying Based on Virtual Tactile Perspective. Journal of Management, 11(1), 133.

Zhao, H. X., Wang, X. H., \& Zhou, B. G. (2015). Research on the Relationship between Online Interaction, Presence and Consumer Trust in B2C Online Shopping. Journal of Management Review, 27(2), 43-54.

Zhao, L., \& Luo, Y. (2008). Research on the Influence of Consumer Characteristics on Online Promotional Activities. Journal of National Business Situation (Research of Economic Theory), 8(8), 51-52.

Zhao, Y. N. (2010). Research on the influence factors of website environment on consumers' impulse purchase. Dissertation. Jilin: Jilin University.

Zhou, G. L. (2011). Research on Perceived Risk and Purchase Intention of Online Group Buying Consumers. Journal of Henan Commercial College, 24(6), 37-41.

\section{Copyrights}

Copyright for this article is retained by the author(s), with first publication rights granted to the journal.

This is an open-access article distributed under the terms and conditions of the Creative Commons Attribution license (http://creativecommons.org/licenses/by/4.0/). 